ISSN: $2338-4794$

Vol.6. No. 3 September-Desember 2018

\title{
PENGARUH KUALITAS PRODUK DAN PROMOSI TERHADAP KEPUTUSAN PEMBELIAN
}

\author{
Bongsu Saragih*) \\ *)Dosen Program Studi Manajemen FE Unkris \\ Alamat: Kampus Unkris Jatiwaringin, Jakarta \\ Email: bongsu.saragih@gmail.com
}

\begin{abstract}
Bastard Clothing is a home industry that is also used as a brand or brand T-shirt distro that began to appear in early 2015. Promotion of the right target and good product quality greatly affect the community (consumers) in making the purchase of these products. Product quality greatly affects consumer purchasing decisions on a product, a good product in terms of quality or price will not be easy to compete if it is wrong in doing promotional activities. This study aims to analyze the contribution of simultaneous between product quality and promotion to purchase decision, analyze the partial contribution between product quality to a decision of purchasing and analyze the contribution of partially between promotion to purchasing. Samples in this research counted 44 respondents. The analysis technique used multiple regression analysis. The results of the analysis show that promotion and product quality simultaneously have a significant contribution on purchasing decisions, which means that the more attractive promotions made by companies and products offered quality can improve purchasing decisions. Product quality affects purchasing decisions, it indicates that the more quality products offered to consumers can improve purchasing decisions. Promotion contribution purchasing decisions, indicating that the more companies promotion can improve purchasing decisions.
\end{abstract}

Keywords: Product quality, promotion, purchase decision

\section{PENDAHULUAN}

Bastard Clothing merupakan
industri rumahan yang sekaligus dijadikan suatu brand atau merk kaos distro yang mulai muncul di awal tahun 2015. Segmentasi pasar Bastard Clothing lebih ditujukan ke anak muda karena produk yang dikeluarkan selama ini adalah kaos distro dengan motif gambar dengan tema yang berbeda-beda. Menurut Kotler dan Armstrong (2008), keputusan pembelian konsumen adalah membeli merek yang paling disukai dari berbagai alternatif yang ada, tetapi dua faktor bisa berada antara niat pembelian dan keputusan pembelian. Faktor pertama adalah sikap orang lain dan faktor yang kedua adalah faktor situasional.

Berdasarkan penjelasan tersebut, tujuan dalam penelitian ini adalah untuk menganalisis pengaruh kualitas produk dan harga terhadap keputusan pembelian baik secara simultan maupun parsial. Hasil penelitian ini diharapkan bermanfaat bagi semua pihak.

\section{LANDASAN TEORI}

\section{Kualitas Produk}

Menurut Kotler dan Amstrong
(2012) kualitas produk adalah
kemampuan suatu produk untuk
melaksanakan fungsinya, meliputi daya
tahan, keandalan, ketepatan, kemudahan
operasi dan perbaikan, serta atribut
bernilai lainnya. Menurut Tjiptono


(2005), kualitas produk adalah sebagai gambaran langsung dari suatu produk seperti performasi, keandalan, mudah dalam penggunaan, estetika dan sebagainya menurut pendapat.

Dimensi kualitas produk menurut Mullins et al. (2005) terdiri dari : kinerja (Performance) yaitu berhubungan dengan karakteristik operasi dasar dari sebuah produk. daya tahan (Durability), yang berarti berapa lama umur produk bertahan sebelum produk tersebut harus diganti. kesesuaian dengan spesifikasi (Conformance to specifications), yaitu sejauh mana produk memenuhi spesifikasi atau tidak ditemukannya cacat pada produk. Fitur (Features), adalah karakteristik produk yang dirancang untuk menyempurnakan fungsi produk atau ketertarikan konsumen terhadap produk. Reliabilitas (Reliabilty), adalah probabilitas bahwa produk akan bekerja dengan memuaskan atau tidak dalam periode waktu tertentu. Estetika (Aesthetics), berhubungan dengan bagaimana penampilan produk. kesan kualitas (Perceived quality), sering dibilang merupakan hasil dari penggunaan pengukuran yang dilakukan secara tidak langsung karena terdapat kemungkinan bahwa konsumen tidak mengerti atau kekurangan informasi atas produk yang bersangkutan.

\section{Promosi}

Menurut Kotler (2009) promosi merupakan berbagai kegiatan yang dilakukan antar perusahaan untuk mengkomunikasikan manfaat dari produknya dan untuk meyakinkan konsumen sasaran agar membelinya. Menurut Gitosudarmo (2000) menyatakan "promosi merupakan kegiatan yang di tujukan untuk mempengaruhi konsumen agar mereka menjadi kenal akan produk yang ditawarkan oleh perusahaan kepada mereka dan mereka menjadi senang lalu membeli produk itu". Sedangkan menurut
Babin (2011) promosi merupakan fungsi komunikasi dari perusahaan yang bertanggung jawab menginformasikan dan membujuk atau mengajak pembeli. Lupiyoadi (2001), menyatakan bahwa promosi merupakan suatu tindakan yang di dalamnya terdapat aktifitas periklanan (advertising), penjualan perorangan (personal selling), promosi penjualan (sales promotion), dan hubungan masyarakat (public relation).

\section{Keputusan Pembelian}

Menurut Kotler dan Armstrong (2008), keputusan pembelian adalah membeli merek yang paling disukai dari berbagai alternatif yang ada, tetapi dua faktor bisa berada antara niat pembelian dan keputusan pembelian. Menurut Drumond (2003), adalah mengidentifikasikan semua pilihan yang mungkin untuk memecahkan persoalan itu dan menilai pilihan-pilihan secara sistematis dan obyektif serta sasaransasarannya yang menentukan keuntungan serta kerugiannya masing - masing.

\section{METODE PENELITIAN}

Penelitian ini merupakan penelitian yang mendeskripsikan hubungan kausalitas antara kualitas produk dan promosi dengan keputusan pembelian melalui pengujian hipotesis. Penelitian ini adalah penelitian survei melalui penyebaran kuesioner dengan unit analisis individu yaitu pelanggan Bastard Clothing

Penelitian dilakukan pada perusahaan Bastard Clothing yang berada di Jalan Transad Raya RT 002 RW 008 No. 66 Kelurahan Jatiranggon Kecamatan Jatisampurna Kota Bekasi, Jawa Barat. Data yang dikumpulkan adalah data primer yang diperoleh dari para pelanggan melalui pengisian daftar pernyataan pada kuesioner dengan menggunakan skala Likert. Skala Likert yang digunakan adalah sangat setuju 
dengan bobot 5 , setuju dengan bobot 4 , netral dengan bobot 3 , tidak setuju dengan bobot 2, dan sangat tidak setuju dengan bobot 1 .

Populasi dalam penelitian ini adalah seluruh pelanggan Bastard Clothing. Teknik pengambilan sampel menggunakan teknik accsident sampling, yaitu pelanggan yang berkunjung ke Bastard Clothing selama kurun waktu 3 bulan yang berjumlah keseluruhan yaitu 44 pelanggan..

Untuk menganalisis pengaruh kualitas produk dan promosi terhadap keputusan pembelian digunakan metode analisis regresi berganda (Multiple Regresion) dengan rumus sebagai berikut:

$$
\mathrm{Y}=\mathrm{a}+\mathrm{b} 1 \mathrm{X} 1+\mathrm{b} 2 \mathrm{X} 2
$$

Keterangan:

$$
\begin{array}{ll}
\mathrm{Y} & =\text { Keputusan Pembelian } \\
\mathrm{a} & =\text { Konstanta } \\
\mathrm{b}_{1} \mathrm{~b}_{2} & =\text { Koefisien regresi } \\
\mathrm{X}_{1} & =\text { Kualitas Produk } \\
\mathrm{X}_{2} & =\text { Promosi }
\end{array}
$$

Untuk menganalisis pengaruh kualitas produk terhadap keputusan pembelian digunakan metode analisis regresi sederhana (Simple Regresion) dengan rumus sebagai berikut:

$$
\mathrm{Y}=\mathrm{a} 1+\mathrm{b} 1 \mathrm{X} 1 \ldots \ldots \ldots
$$

Keterangan:

$$
\begin{aligned}
\mathrm{Y} & =\text { Keputusan Pembelian } \\
\mathrm{a} & =\text { Konstanta } \\
\mathrm{b}_{1} & =\text { Koefisien regresi } \\
\mathrm{X} 1 & =\text { Kualitas Produk }
\end{aligned}
$$

Untuk menganalisis pengaruh promosi terhadap keputusan pembelian digunakan metode analisis regresi sederhana (Simple Regresion) dengan rumus sebagai berikut:

$$
\mathrm{Y}=\mathrm{a} 2+\mathrm{b} 2 \mathrm{X} 2
$$

Keterangan:

$$
\begin{aligned}
\mathrm{Y} & =\text { Keputusan Pembelian } \\
\mathrm{a} & =\text { Konstanta } \\
\mathrm{b}_{2} & =\text { Koefisien regresi } \\
\mathrm{X}_{2} & =\text { Promosi }
\end{aligned}
$$

\section{HASIL PENELITIAN DAN PEMBAHASAN}

\section{Hasil Penelitian}

\section{Uji Validitas dan Reliabilitas}

Berdasarkan hasil uji validitas dan uji reliabilitas data yang diteliti, yaitu kualitas produk, promosi dan keputusan pembelian menunjukkan bahwa setiap butir pernyataan yang diajukan kepada responden dinyatakan valid dan reliabel. Hal ini berarti bahwa responden telah memahami setiap pernyataan yang diajukan dan responden konsisten pada butir pernyataan yang ditentukan.

\section{Analisis Regresi Linier Berganda}

Analisis regresi linier berganda digunakan untuk mengetahui besarnya pengaruh dari variabel promosi dan kualitas produk terhadap keputusan pembelian. Hasil perhitungan dapat dilihat pada tabel berikut : 
Tabel 1

Rekapitulasi Hasil Analisis Regresi Linier Berganda

\begin{tabular}{lccc}
\hline \multicolumn{1}{c}{ Variabel } & Koefisien Regresi & $\mathrm{t}_{\text {hitung }}$ & Sig. \\
\hline Promosi & 0,646 & 6,729 & 0,000 \\
Kualitas produk & 0,372 & 3,782 & 0,000 \\
\hline Konstanta & $-0,038$ & \\
$\mathrm{R}$ & 0,904 & \\
$R$ square & 0,817 & \\
$\mathrm{~F}_{\text {hitung }}$ & 91,815 & \\
Sig. F & 0,000 & \\
$\mathrm{n}$ & 44 & \\
\hline Variabel terikat $=$ Keputusan pembelian $(\mathrm{Y})$ & & \\
\hline
\end{tabular}

Sumber : Data primer diolah.

Hasil perhitungan regresi berganda tersebut dapat diketahui formulasinya sebagai berikut :

$$
Y=-0,038+0,646 X_{1}+0,372 X_{2}
$$

Berdasarkan hasil persamaan tersebut, maka dapat dijelaskan sebagai berikut : a). Konstanta (a) $=-0,038$ menunjukkan besarnya keputusan pembelian, jika tidak ada promosi dan kualitas produk maka besarnya keputusan pembelian sebesar $-0,038$. b). Koefisien regresi promosi sebesar 0,646, menunjukkan besarnya pengaruh promosi terhadap keputusan pembelian, koefisien regresi bertanda positif menunjukkan promosi berpengaruh searah terhadap keputusan pembelian, yang berarti semakin sering melakukan promosi akan menyebabkan peningkatan keputusan pembelian. c). Koefisien regresi kualitas produk sebesar 0,372, menunjukkan besarnya pengaruh kualitas produk terhadap keputusan pembelian, koefisien regresi bertanda positif menunjukkan kualitas produk berpengaruh searah terhadap keputusan pembelian, yang berarti semakin tinggi kualitas produk akan menyebabkan peningkatan keputusan pembelian.

Koefisien korelasi berganda (R) sebesar 0,904; menunjukkan bahwa secara bersama-sama terdapat hubungan yang sangat kuat dan searah antara promosi dan kualitas produk dengan keputusan pembelian sebesar 90,4\%. Hubungan ini dapat dikategorikan sangat kuat, sebagaimana diketahui bahwa suatu hubungan dikatakan sempurna jika koefisien korelasinya mencapai angka $100 \%$ atau 1 (baik dengan angka positif atau negatif).

Dari hasil analisis regresi linier berganda, dapat diketahui nilai koefisien determinasi ( $R$ square) sebesar 0,817. Angka ini menunjukkan bahwa variabel promosi dan kualitas produk dapat menjelaskan variasi atau mampu memberikan kontribusi terhadap variabel keputusan pembelian sebesar 81,7\%, sedangkan sisanya sebesar $18,3 \%$ disebabkan oleh variabel lain yang tidak dimasukkan dalam penelitian.

\section{Hasil Uji Hipotesis}

1). Pengujian Hipotesis Pertama; Untuk menguji hipotesis pertama yang menyatakan ada pengaruh secara simultan antara promosi dan kualitas produk terhadap keputusan pembelian, dengan menggunakan uji $\mathrm{F}$. Uji $\mathrm{F}$ digunakan untuk mengetahui signifikansi pengaruh variabel bebas promosi dan kualitas produk secara simultan berpengaruh signifikan terhadap 
keputusan pembelian. Apabila besarnya $\mathrm{F}_{\text {hitung }}>\mathrm{F}_{\text {tabel, }}$ maka Ho ditolak dan $\mathrm{Ha}$ diterima.

Dari hasil perhitungan analisis regresi berganda dengan SPSS diperoleh $F_{\text {hitung }}$ sebesar 91,815 , sedangkan $F_{\text {tabel }}$ pada $\alpha=5 \%, \mathrm{df}_{1}=2$, dan $\mathrm{df}_{2}=41$ sebesar 3,23; hal ini berarti $F_{\text {hitung }}>F_{\text {tabel }}$ $(91,815>3,23)$ sedangkan nilai probabilitasnya lebih kecil dari $\alpha=$ $0,05(0,000<0,05)$, maka Ho ditolak dan Ha diterima yang berarti bahwa variabel bebas : promosi dan kualitas produk secara simultan berpengaruh signifikan terhadap keputusan pembelian. Dengan demikian hipotesis pertama secara statistik dapat diterima atau teruji.

2). Pengujian Hipotesis Kedua; Untuk menguji hipotesis kedua yang menyatakan bahwa ada pengaruh secara parsial antara promosi terhadap keputusan pembelian, dengan menggunakan uji t. Hasil uji t promosi diperoleh nilai $\mathrm{t}_{\text {hitung }}=6,729$ sedangkan nilai $\mathrm{t}_{\text {tabel }}=2,021$ sehingga $\mathrm{t}_{\text {hitung }}>\mathrm{t}_{\text {tabel }}$ atau nilai signifikansi $0,000<0,05$ jadi Ho ditolak atau Ha diterima, sehingga terbukti variabel promosi berpengaruh signifikan terhadap keputusan pembelian. Dengan demikian hipotesis kedua secara statistik teruji.

3). Pengujian Hipotesis Ketiga; Untuk menguji hipotesis ketiga yang menyatakan bahwa ada pengaruh secara parsial antara kualitas produk terhadap keputusan pembelian, dengan menggunakan uji t. Hasil uji t kualitas produk diperoleh nilai $t_{\text {hitung }}=3,782$ sedangkan nilai $t_{\text {tabel }}=2,021$ sehingga $t_{\text {hitung }}>\mathrm{t}_{\text {tabel }}$ atau nilai signifikansi 0,000 $<0,05$ jadi Ho ditolak atau Ha diterima, sehingga terbukti variabel kualitas produk berpengaruh signifikan terhadap keputusan pembelian. Dengan demikian hipotesis ketiga secara statistik teruji.

\section{Pembahasan}

\section{Pengaruh Promosi dan Kualitas Produk terhadap Keputusan Pembelian}

Berdasarkan hasil analisis menunjukkan bahwa promosi dan kualitas produk berpengaruh terhadap keputusan pembelian dan mampu memberikan kontribusi yang cukup besar terhadap kecenderungan seseorang dalam keputusan pembelian di Distro Bastard Clothing sbagaimana konsep Babin (2011), promosi merupakan fungsi komunikasi dari perusahaan yang bertanggung jawab menginformasikan dan membujuk atau mengajak pembeli.

\section{Pengaruh Promosi terhadap Keputusan pembelian}

Hasil penelitian menunjukkan bahwa Promosi dapat meningkatkan keputusan pembelian yaitu penjualan pribadi tercermin dari para reseller memudah mendapatkan produk sebagaimana konsep Kotler (2010) yang menyatakan bahwa promosi merupakan berbagai kegiatan yang dilakukan antar perusahaan untuk mengkomunikasikan manfaat dari produknya dan untuk meyakinkan konsumen sasaran agar membelinya.

\section{Pengaruh Kualitas produk terhadap Keputusan pembelian}

Hasil penelitian menunjukkan bahwa Kualitas produk berpengaruh signifikan terhadap keputusan pembelian. Kualitas produk dalam penelitian ini yang dapat meningkatkan keputusan pembelian adalah reliability tercermin dari bahan kaos sangt lembut dan nyaman. Semakin banyak jenis dan macam produk, serta semakin berkualitas, maka konsumen akan tertarik untuk menggunakan kaos Bastard Clothing sebagaimana konsep Kotler dan Amstrong (2012:283) yang menyatakan bahwa kualitas produk adalah kemampuan suatu produk untuk 
melaksanakan fungsinya, meliputi daya tahan, keandalan, ketepatan,

\section{KESIMPULAN DAN SARAN}

\section{Kesimpulan}

Hasil analisa dalam penelitian ini dapat disimpulkan bahwa kualitas produk dan promosi secara simultan dan parsial berkontribusi terhadap keputusan pembelian.

\section{Saran-saran}

Kualitas produk dan promosi sebagai factor pendorong peningkatan keputusan pembelian tetap dipertahankan dan perlu ditingkatkan. Penelitian selanjutnya dapat mempertimbangkan kualitas produk dan promosi sebagai variable yang memediasi (intervening variable) terhadap keputusan pembelian.

\section{DAFTAR PUSTAKA}

Babin, 2011. Menjelajahi Riset Pemasaran. Penerbit Salemba Empat. Jakarta.

Drumond, Helga. 2003. Metode Penelitian Bisnis. Jilid I. Edisi Kelima. Erlangga, Jakarta.

Engel, 1993. Perilaku Konsumen. Edisi 6, Binarupa Aksara. Jakarta.

Gasperz, Vincent. 2004. Production Planning and Inventory Control, PT. Gramedia Pustaka Umum. Jakarta.

Gitosudarmo, Indriyo. 2000. Manajemen Pemasaran. Edisi 2. BPFE. Yogyakarta.

Kotler, Philip dan Gary Armstrong. 2012. Prinsip-prinsipPemasaran. Edisi.

13. Jilid 1. Erlangga. Jakarta. 2009. Prinsip-Prinsip Pemasaran, jilid 1, Erlangga, Jakarta. 2008

Pemasaran. Edisi. 12. Jilid 1. Erlanggan. Jakarta:
Kotler Philip, 2009, Manajemen Pemasaran. Jilid 1, Erlangga, Jakarta. 2005. Manajemen Pemasaran. Jilid 2. PT. Indeks. Jakarta.

Kotler, Philip., and Kevin Lane Keller. 2009. Manajemen Pemasaran. Edisi Kedua Belas. Jilid 2, PT. Indeks, Jakarta.

Lupiyoadi, Rambat. 2001. Manajemen Pemasaran Jasa, Teori dan Praktek. Edisi. Pertama. Salemba Empat. Jakarta.

Mullins, Orville, Larreche dan

Boyd. 2005.

Marketing Management: A Strategic,. Decision Making Approach, 6th edition. Penerbit McGraw-Hill. New York City.

Nugroho Riant, 2003, Perilaku Konsumen, Kencana, Jakarta.

Priyatno, Dwi 2009: 5 Jam Belajar Olah Data dengan SPSS 17. Andi. Yogyakarta.

Purwanto, Asih. 2008. Pengaruh Kualitas Produk, Promosi dan Design Terhadap Keputusan Pembelian Kendaraan Bermotor Yamaha Mio. Skripsi. Fakultas Ekonomi. Universitas Muhammadiyah Surakarta.

Santoso, K.W., Waluyo, H.D. \& Listyorini, S. 2013. Pengaruh Kualitas Produk, Harga dan Promosi Terhadap Keputusan Pembelian Permen Tolak Angin di Semarang. Diponegoro Journal of Social and Politic. Vol 8 (1): 1-10.

Schiffman dan Kanuk. 2007. Perilaku Konsumen. Edisi Kedua. PT. Indeks. Gramedia. Jakarta.

Setiawati, Bekti. 2006. Pengaruh Kualitas Produk, dan Promosi Terhadap Keputusan Pembelian Kerupuk Rambak Dwijoyo di Desa Penanggulan Kecamatan Penanggon Kabupaten Kendal. Skripsi. Fakultas Ilmu Sosial. Universitas Negeri Semarang. 
Simamora, Henry. 2002. Manajemen Pemasaran Internasional. Jilid 1 Edisi Cetak. 1. Salemba Empat. Jakarta.

Sugiyono. 2010. Metode Penelitian Pendidikan Pendekatan Kuantitatif, kualitatif, dan $R \& D$. Alfabeta. Bandung.

Sutisna. 2001. Perilaku Konsumen dan Komunikasi Pemasaran. PT. Remaja Rosdakarya. Bandung.
Swastha, Basu dan T. Hani Handoko. 2008. Manajemen Pemasaran, Analisa Perilaku Konsumen. Edisi Pertama, Cetakan Keempat, Penerbit: BPFE, Yogyakarta.

Tjiptono, Fandy. 2005. Pemasaran Jasa. Bayu Media Publising. Malang. 
